\title{
Positive periodic solutions for systems of second order differential equations
}

\section{VASILE DINCUŢ̧ă-TĂNASE}

\section{ABSTRACT.}

In this paper we seek for positive periodic solutions for a system of second order differential equations using a vector version of Krasnoselskii's Fixed Point Theorem in Cones. This makes possible that the nonlinear term of the system have different behaviors both in components and variables.

\section{REFERENCES}

[1] Cheng, X., Existence of positive solutions for a class of second-order ordinary differential systems, Nonlinear Anal. 69 (2008), 3042-3049

[2] Krasnoselskii, M., Positive solutions of operator equations, Noordhoff, Groningen, 1964

[3] Jiang, D., Chu, J., O’Regan D. and Agarwal, R., Multiple positive solutions to superlinear periodic boundary value problems with repulsive singular forces, J. Math. Anal. Appl. 286 (2003), 563-576

[4] O'Regan, D. and Wang, H., Positive periodic solutions of systems of second order ordinary differential equations, Positivity 10 (2006), 285-298

[5] Precup, R., A vector version of Krasnoselskii's fixed point theorem in cones and positive periodic solutions of nonlinear systems, J. Fixed Point Theory Appl. (Birkhauser) 2 (2007), No. 1, 141-151

[6] Torres, P., Existence of one-signed periodic solutions of some second-order differential equations via a Krasnoselskii fixed point theorem, J. Diff. Eq. 190 (2003), 643-662

[7] Wang, H., On the number of positive solutions of nonlinear systems, J. Math. Anal. Appl. 281 (2003), 287-306

TECHNICAL UNIVERSITY OF CLUJ-NAPOCA

DEPARTMENT OF MATHEMATICS

C. Daicoviciu 15, 400020 Cluj-Napoca, Romania

E-mail address: Vasile.Dincuta@math.utcluj.ro 